\title{
UN DÍA 10 SIN VER LA TELEVISIÓN
}

\section{ONE DAY 10 WITHOUT WATCHING TV}

\section{Asociación Plaza del Castillo de Usuarios de Medios de Comunicación plazadelcastillo@hotmail.com}

\section{CURRÍCULUM VITAE}

La Asociación Plaza del Castillo de Usuarios de Medios de Comunicación, Telespectadores y Radioyentes es una organización profesional, aconfesional y apartidista que representa los intereses y derechos de los usuarios ante los medios de comunicación.

Como ATR Navarra están integrados en FIATYR (Federación Ibérica de Telespectadores y Radioyentes), que cuenta con representación en todas las comunidades de España, Portugal y Andorra. Es socio fundador de Euralva (European Alliance of Listeners and Viewers Association) con sede en el condado de Kent, Reino Unido. Es Miembro del Consejo Mundial de la Radio y la Televisión (CMRTV) (WRTVE) con sede en Canadá y Suiza.

Los miembros de la Asociación Plaza del Castillo ponen a su servicio Mediatics, un equipo de comunicadores profesionales y de expertos en pedagogía, psicología, derecho y filosofía dispuestos a escuchar sus dudas y problemas y ofrecerles soluciones realistas y concretas. Seguirá reivindicando cambios en las estructuras empresariales de los productores de contenidos y un mayor control por parte de los poderes públicos, no lo duden. 


\title{
RESUMEN
}

Desde la Federación Ibérica de Telespectadores y Radioyentes se ha creado una nueva campaña por una televisión de calidad. El espectador en España esta desprotegido porque no existe una Autoridad Audiovisual con poder sancionador. $\mathrm{Al}$ respecto de este tema se exponen diferentes aspectos que influyen, como la necesidad de una televisión de titularidad pública, el respeto al horario de protección del menor, o la televisión basura. Cada tema incluye un apartado de su normativa correspondiente.

\section{PALABRAS CLAVE}

Televisión - Autoridad Audiovisual - Protección del menor - Telebasura - Pública

\begin{abstract}
From the Iberian Federation of Viewers and Listeners have created a new campaign for quality television. The spectator in Spain is unprotected because there is no Audiovisual Authority with powers of sanction. Regarding this issue presents different aspects that influence, as the need for a publicly owned television, respect the schedule of child protection, or trash television. Each issue includes a section of relevant regulations.
\end{abstract}

\section{KEY WORDS}

TV - Audiovisual Authority - Child protection - Junk TV - Public 
TEXTO:

IX CAMPAÑA

10 DE MAYO DE 2007

A favor de una televisión de calidad

PREMISAS

TELEVISIÓN DE TITULARIDAD PÚBLICA

RESPETO AL HORARIO DEL MENOR

PROGRAMACIÓN CINEMATOGRÁFICA

TELEVISIÓN BASURA. TELEREALIDAD

PRESIÓN PUBLICITARIA

FUNDAMENTACIÓN NORMATIVA

Información y Adhesiones:

Asociación Plaza del Castillo de Usuarios de Medios de Comunicación.

plazadelcastillo@hotmail.com

www.asociacionplazadelcastillo.org

www.atr.org.es

Federación Ibérica de Telespectadores y Radioyentes. (FIATYR)

nunovonamann@yahoo.com

atrmadrid@infonegocio.com

INTRODUCCIÓN

Creación de una Autoridad Audiovisual 
Desde la Federación Ibérica de Telespectadores y Radioyentes (FIATYR), nos acercamos a cuantas instituciones, organismos, asociaciones y ciudadanos en general, consideren el poder e influencia que los medios de comunicación y en particular la televisión ejercen en nuestra sociedad y muy especialmente cara a las nuevas generaciones (frecuentemente tienen "una visión televisiva del mundo"), para que si comparten las premisas de ésta campaña, y la campaña en si misma, la defiendan y la divulguen todo lo que esté en su mano y dejen de ver la televisión las 24 horas del próximo

\section{DE MAYO DE 2007}

"por una televisión de calidad"

Al presentar las premisas de la campaña mantenemos en primer lugar, que el grado de indefensión del espectador en España es mayor, puesto que no existe una Autoridad Audiovisual con poder sancionador, organismo que venimos reclamando durante los últimos quince años.

Hasta el año 1996 estando el Partido Socialista Obrero Español en el poder, desde 1996 ostentándolo el Partido Popular, hasta el 2004 en que gana las elecciones de nuevo el P.S.O.E.

Considerando la intoxicación interesada de periodistas y tertulianos en el último año, así como la errónea politización del tema, hay que reseñar en éste sentido, el silencio de gran parte de la clase política, de los ámbitos sociales más influyentes, muy especialmente de los responsables y profesionales del poder mediático español, contrarios en su mayor parte a la institucionalización de ésta figura e ignorantes de la preocupación y desmoralización que ésta realidad engendra en muchas familias españolas. 
La Autoridad Audiovisual, organismo vivo e imprescindible en todo país civilizado y democrático, existe en todas las naciones desarrolladas y aún en vías de desarrollo y desde luego en la totalidad de nuestro entorno europeo: Francia, Italia, Inglaterra, Irlanda, Países Bajos, Portugal, así como en Grecia, Turquía, etc.

En España, es urgente su creación, una autoridad que debe emanar de la Ley del Audiovisual: independiente y con poder sancionador.

Desde EURALVA (European Alliance of listeners and viewers Asociation), de la que somos miembros fundadores, en el encuentro internacional que tuvo lugar en Lisboa el mes de Enero de 2006 , ya se reclamó a la Comisión Europea la vigilancia en el cumplimiento por parte de España del órgano regulador que contempla la propia Directiva de Televisión sin Fronteras.

Su urgente creación, demandada por amplios sectores de la sociedad española, se hace especialmente necesaria en relación con otros temas que también preocupan al espectador español, algunos de los cuales componen las premisas de ésta campaña: la televisión de servicio público; la protección del horario del menor; la televisión basura; la programación cinematográfica; la presión publicitaria ,etc.

No podemos dejar de señalar aquí el tema de la contraprogramación (la normativa más permisiva de Europa y sin embargo se ha readaptado nuevamente a favor de las empresas).A la contraprogramación le dedicamos, en parte, la campaña del año 2004 y es una práctica siempre perjudicial para el espectador, que venimos denunciando ante la Comisión Europea en Noviembre de 2001 y ante el Consejo Audiovisual de Navarra en nuestra comparecencia de Octubre de 2002. 
La campaña consta de los apartados referidos, poniendo de manifiesto sintéticamente, sus principales extremos; a continuación se fundamenta la normativa legislativa correspondiente, española y comunitaria.

I.- A favor de una televisión de titularidad pública

Como se expresa en su propio estatuto:"De servicio público esencial." Próxima a la cultura de la comunidad a la que sirve. Independiente de todo poder partidista y mediático. De tamaño humano: controlable económicamente. Al servicio de los ciudadanos y no del poder.

Contribuyendo al desarrollo de nuestra lengua (400 millones de hispanohablantes) y cultura.

La política audiovisual errónea que se practica en el ente público, lleva a que, excepcionalmente, y por lo general en la segunda cadena (a veces en horarios inverosímiles) se emita una programación digna; lo que es inaceptable es que se diga que es "para una inmensa minoría"; la calidad es para todos; todos y cada uno de los espectadores tenemos derecho a lo mejor.

Hoy, la televisión pública no cumple con el cometido que le es propio: informar, formar y divertir.

Sabemos que se va a llevar a cabo una reestructuración drástica en el terreno económico y laboral, pero nos preguntamos si servirá para cambiar la mentalidad de los responsables en orden a mejorar la programación.

Simultáneamente con ésta campaña pensamos hacer llegar al defensor del espectador de RTVE.y a la opinión pública, una larga lista de programas que consideramos 
incompatibles con el servicio público, la pluralidad y la calidad que le deben ser propios.

Incompatible con la televisión pública: la innumerable cantidad de horas dedicadas a tratar la llamada crónica rosa, y muy especialmente al contenido basado en la crónica negra diaria.

Algunas consideraciones que mejorarían la oferta:

La calidad en la información y en los contenidos, realizada con creatividad y talento; suficientemente publicitada y ubicada en horarios de máxima audiencia.

El referente de nuestra historia y cultura.

La representación de la rica pluralidad española, ideológica y socialmente hablando.

El respeto escrupuloso a la normativa vigente en materia de información, contenidos y publicidad.

FUNDAMENTACIÓN NORMATIVA

La ley 4/1980 de 10 de enero, aprueba el Estatuto de la Radio y Televisión y califica ambos medios como servicios públicos de titularidad estatal, cuya gestión directa se encomienda al Ente Público. Los principios de esta actividad deben plasmar el precepto constitucional (Art. 20 Constitución Española) de objetividad, veracidad, imparcialidad, separación de opiniones e informaciones y respeto al pluralismo.

La Ley 10/1998 de 3 de mayo de televisión privada dice en su preámbulo:" la finalidad de la televisión como tal servicio público ha de ser ante todo, la de 
satisfacer el interés de los ciudadanos y la de contribuir al pluralismo informativo, a la formación de una opinión pública libre y a la extensión de la cultura."

II.- Respeto al horario de protección del menor

Uno de los aspectos que más preocupa a la sociedad española.

Cumpliendo la normativa vigente española y comunitaria; Por la recuperación de la programación infantil en su horario natural de tarde ( hoy prácticamente desaparecida de las televisiones ,tanto públicas como privadas).

Favoreciendo la producción española y europea ante las procedentes de otras culturas: japonesa y americana principalmente, por lo general, con mayores dosis de violencia.

Creación de comités de expertos independientes que analicen, diseñen y propongan una programación adecuada; evitando drásticamente los contenidos que puedan afectar a los menores y muy especialmente en los avances de programas o películas que se van a emitir en horarios para adultos en los que se suele exhibir las escenas más escabrosas y violentas. Por ahora y por lo que sabemos, ninguno de los códigos de protección del horario del menor, firmados por las cadenas: en 1993 y en 2004 ha supuesto ningún cambio en ésta práctica indeseable; antes bien, tenemos la impresión de que mantienen un pulso con el gobierno en el que, por ahora, ganan.

Según reconocen los expertos:"España sigue siendo uno de los países de la Unión Europea menos selectivos en la programación de dibujos animados.";"Los contenidos dedicados a infancia han sido los más sacrificados en las parrillas televisivas" 
Se hace necesario considerar prioritarios el ocio y la diversión (a los que se debería dedicar los mayores recursos), primar los contenidos positivos, plasmados arriesgando en la forma y que divulguen valores éticos; estéticos; solidarios. Pero al mismo tiempo fomentar el amor al conocimiento de nuestras raíces culturales, de la historia, de la lengua y literatura, de la ciencia y la tecnología, la naturaleza, etc. en la forma más moderna y vanguardista, utilizando los últimos avances técnicos con los que las nuevas generaciones mejor se relacionan.

\section{FUNDAMENTACIÓN NORMATIVA}

La Ley25/1994 de 12 de julio por la que se incorpora al ordenamiento jurídico español la Directiva 89/552/CEE regula en su Art. 17 la Protección de los Menores frente a la programación dejando claro que las emisiones de televisión no incluirán programas ni escenas o mensajes de cualquier tipo que puedan perjudicar seriamente el desarrollo físico, mental o moral de los menores, ni programas que fomenten el odio o la discriminación.

La emisión de programas susceptibles de perjudicar el desarrollo físico, mental o moral de los menores, y en todo caso, de aquellas que contengan escenas de pornografía o de violencia gratuita, solo podrá realizarse entre las 22 y las 6 horas y deberá ser objeto de advertencia sobre su contenido por medios acústicos y ópticos.

\section{PROGRAMACIÓN CINEMATOGRÁFICA}

Cambio radical en la política cinematográfica muy especialmente en la televisión de titularidad pública: profesionales que conozcan, respeten el cine y sepan divulgarlo, mostrando movimientos y ciclos de calidad, directores, actores, géneros; incluyendo cinematografías clásicas, comerciales, experimentales o exóticas,(no solo procedentes de los mismos países), fomentando la cultura cinematográfica . 
En cuanto a la publicidad, la inducción a que nos abonemos a cualquier canal de pago para ver cine razonablemente, queda muy claro para cualquier cinéfilo.

Cine de estreno. Largometrajes; cortometrajes; animación.

Cumplimiento de la normativa vigente en toda materia, muy especialmente en cuanto a las interrupciones publicitarias.

Dedicación urgente a las versiones originales subtituladas, en horarios razonables.

Evitar las repeticiones.

Horarios de máxima audiencia.

Retransmisiones en abierto y directo de muestras y festivales, nacionales e internacionales.

Apoyo a la producción europea.

\section{FUNDAMENTACIÓN NORMATIVA}

La ley 25/1994 de 12 de julio regula en su Capítulo II la promoción difusión y producción de determinados programas televisivos. En su Art 5 regula que las Entidades que presten directa o indirectamente el Servicio Público deberán reservar el 51 por 100 de su tiempo de emisión anual a la difusión de obras europeas. Añade que mas del 50 por 100 del tiempo de reserva, se guardar para obras en versión original. 
En su Art. 13 regula el tema de las interrupciones televisivas señalando que las obras audiovisuales, como largometrajes cinematográficos, cuya duración programada de transmisión sea superior a 45 minutos, podrán ser interrumpidas una vez por cada periodo completo de 45 minutos. Estas interrupciones deberán respetar la integridad y el valor de las mismas

\section{III.- Televisión basura}

Nos manifestamos radicalmente contrarios a la televisión basura, cada vez más presente en todas las televisiones, en horario de máxima audiencia, incluido el horario de protección del menor, a pesar de la firma de todas las cadenas, de titularidad pública y privada del código deontológico.

Es uno de los fenómenos socialmente más demoledores que existen, con incalculables efectos nocivos en las nuevas generaciones:

exaltación de los más bajos instintos; acoso a la intimidad; progresiva utilización de cámaras ocultas.

fomento de una contracultura de lo más abyecto, grosero, vulgar y cutre: mostrando el escaparate infame de una sociedad falsa, manipulada por unos pocos en su propio beneficio. Simultáneamente se fomenta la venta de un cierto tipo de prensa llamada "rosa" (en realidad es amarilla, sensacionalista), que de otra forma nunca hubiera tenido presencia si no fuera por el inconmensurable poder de la televisión.

El colmo es culpar a los espectadores de ésta lacra, cuando es bien sabido que el responsable de lo emitido es siempre el emisor. La razón por la cual se realiza éste 
tipo de televisión de ínfima calidad es por que resulta muy barata de realizar ya que, a pesar de las intoxicaciones no es, ni mucho menos, lo más visto.

Presencia apabullante y progresiva, ( por fortuna muestra síntomas de agotamiento), de la llamada telerealidad (invento nefasto), que nada tiene que ver con la realidad: es virtual y prefabricada. Ha venido emitiéndose durante los últimos años en todos los horarios y en prácticamente, todas las cadenas.

Manifiesto en contra de la televisión basura de 1997;(extraordinariamente bien definida), firmado por AUC. CAVE. CEAPA, CONCAPA, CC.OO., UGT., OCU, UCE, y 16 Asociaciones de Telespectadores y Radioyentes, Usuarios de Medios de Comunicación Federación Ibérica (FIATYR)

Texto íntegro:

www.asociacionplazadelcastillo.org

\section{FUNDAMENTACIÓN NORMATIVA}

El término " televisión basura" viene dando nombre, desde la pasada década, a una forma de hacer televisión caracterizada por explotar el morbo, el sensacionalismo y el escándalo como palancas de atracción de la audiencia. Especialmente grave es el desprecio por derechos fundamentales recogidos en nuestra Constitución Española; Arts 18 y ss, como el honor, la intimidad familiar y personal, el respeto, la veracidad o la presunción de inocencia, cuya conculcación no puede defenderse en ningún caso apelando a la libertad de expresión.

IV Publicidad. 
Por una menor presión publicitaria, la mayor de Europa. Contraviene la normativa vigente: la ley de publicidad, la directiva comunitaria y el estatuto en cuanto a los bloques publicitarios, la autopromoción y el patrocinio. Algunos presentadores (televisión de titularidad pública), anuncian productos de consumo; tal transgresión hace relativamente poco era impensable.

Es habitual que niños anuncien productos para adultos, aspecto prohibido en la legislación vigente.

Las películas se interrumpen indefinidamente, doblando a veces su duración, cosa que exaspera a los espectadores en general y a los cinéfilos en particular. Es frecuente escuchar a algunos publicitarios afirmar que lo mejor de la programación es la publicidad. Eso es precisamente lo más lamentable: que la televisión se convierta en un catálogo de venta.

Naturalmente que la publicidad puede llegar a ser estética y técnicamente notable, pero la saturación está llegando a no hacerla operativa, cosa que deberían conocer los responsables de su emisión.

Informe sobre la publicidad desde el punto de vista de los usuarios: www.asociacionplazadelcastillo.org

\section{FUNDAMENTACIÓN NORMATIVA}

La Ley25/1994 de 12 de julio por la que se incorpora al ordenamiento jurídico español la Directiva 89/552/CEE y la Ley General de Publicidad 34/1988 de 11 de noviembre regula a nivel normativo la publicidad por televisión y su patrocinio televisivo. El incumplimiento en esta materia es total. El Capítulo III de La ley25/1994 de 12 de julio recoge en su Art. 9 y ss. Entre otras la Publicidad prohibida, 
Publicidad ilícita, regulación específica en materia de Publicidad de bebidas alcohólicas, tiempo de transmisión publicitaria ( "no será superior al 15 por 100 del tiempo diario de emisión" " el tiempo de transmisión dedicado a espacios publicitarios dentro de cada periodo de una hora natural no deberá ser superior a 12 minutos " , Patrocinio televisivo y Protección de los menores.

En las normas reguladoras de la emisión de publicidad por TVE en su apartado 2.11 no se admitirán anuncios en que intervengan sus títulos, personajes, actores o presentadores y en su apartado 3.15 con respecto a la intervención de niños en los anuncios se dice que los niños no pueden ser los actores principales de un anuncio salvo en productos dedicados exclusiva o preferentemente a la infancia o de los que ésta sea beneficiaria.

\section{LEY PARA LA DEFENSA DE LOS CONSUMIDORES Y USUARIOS}

La ley 26/1984 de 19 de Julio general para la Defensa de los Consumidores y Usuarios, art.17:

Los medios de comunicación social de titularidad pública dedicarán espacios y programas no publicitarios, a la información y educación de los consumidores y usuarios. En tales espacios y programas de acuerdo con su contenido y finalidad se facilitará el acceso o participación de las asociaciones de consumidores y usuarios y demás grupos o sectores interesados en la forma que reglamentariamente se determine por los poderes públicos competentes en la materia.

Información y Adhesiones:

Maribel Martinez Eder

Portavoz de FIATYR 
Federación Ibérica de Telespectadores y Radioyentes

plazadelcastillo@hotmail.com

www.asociacionplazadelcastillo.org

(FIATYR):

nunovonamann@yahoo.com

atrmadrid@infonegocio.com

masiloe@teleffonica.net

Marzo 2007. 